\title{
FUNDING DEFENSE: \\ CHALLENGES OF BUYING MILITARY \\ CAPABILITY \\ IN SUB-SAHARAN AFRICA
}

\author{
Daniel W. Henk \\ Martin Revayi Rupiya
}

September 2001 